\title{
An unprecedented photodimerization of an anthraceno[2.2]paracyclophane
}

\author{
William R. Dolbier, Jr.,* Yi-An Zhai, Merle A. Battiste,* Khalil A. Abboud, Ion Ghiviriga, \\ and Kai Wu
}

Department of Chemistry, University of Florida, Gainesville, FL 32611-7200

Email: wrd@chem.ufl.edu

Dedicated to our friend and colleague, Jim Coxon, on the occasion of his $65^{\text {th }}$ birthday

\begin{abstract}
Octafluoro[2.2](1,4)anthraceno-paracyclophane slowly undergoes a clean photodimerization upon being exposed, in solution, to fluorescent light. X-ray crystal analysis of this photodimer indicated that the aromaticity of the anthracene ring directly involved in the paracyclophane system was observed to be destroyed by forming a cyclobutane ring, with the two molecules linked to each other in a head to tail fashion.
\end{abstract}

Keywords: Photochemistry, [2.2]paracyclophane, anthracene, X-ray crystal analysis

\section{Introduction}

As a result of work in our laboratories during the last few years, it has been established that the aryne derived from treatment of 4-iodo-1,1,2,2,9,9,10,10-octafluoro[2.2]paracyclophane (IAF4) ${ }^{1}$ with potassium $t$-butoxide in a non-protic solvent has extraordinary Diels-Alder reactivity with various aromatic substrates, as exemplified by its efficient reaction with naphthalene, shown in Scheme 1. ${ }^{2}$ 

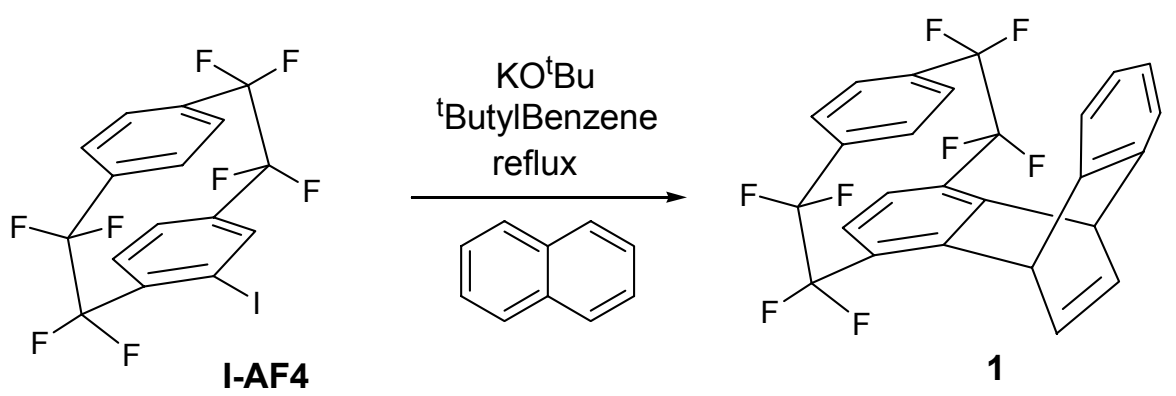

\section{Scheme 1}

It was subsequently demonstrated that such Diels-Alder adducts could be used to prepare novel naphthaleno- and anthraceno-[2.2]phanes (2-5 in Scheme 2) via their one-pot, three step reaction with 3,6-di-(2-pyridinyl)-1,2,4,5-tetrazine, as exemplified in Scheme 3 for the synthesis of $[2.2](1,4)$ anthraceno-paracyclophane, 2. ${ }^{3}$ The process involves first a Diels-Alder cycloaddition to the tetrazine, then loss of $\mathrm{N}_{2}$, and lastly a retro-Diels-Alder reaction to give the product.
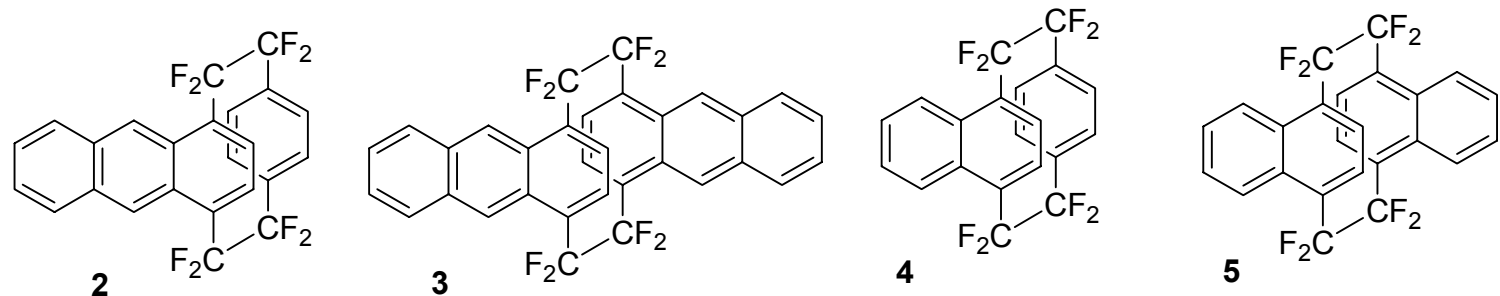

\section{Scheme 2}

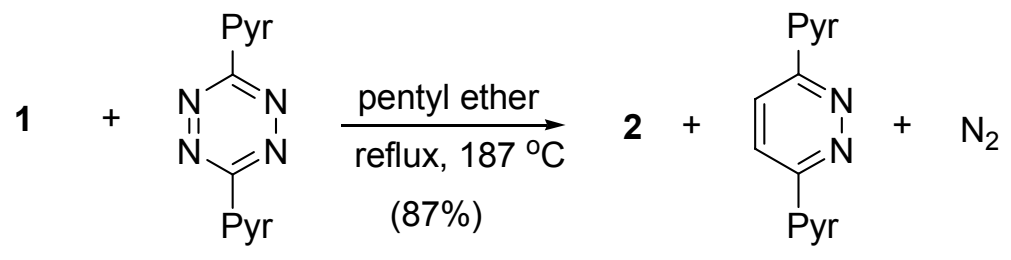

\section{Scheme 3}

During the course of the preparation, purification and characterization of this series of naphthaleno- and anthracenophanes, it was found that $\mathbf{2}$ exhibited an unexpected lability that was uncharacteristic of the other members of the prepared series. When an NMR sample of pure 2 in $\mathrm{CDCl}_{3}$ was allowed to stand for one week at room temperature, it was found that $30 \%$ of 2 had been converted to a new product, which could be separated from $\mathbf{2}$ by column chromatography. 
When characterized, this product turned out to have an unprecedented dimeric structure (Scheme 4), as will be discussed below.

\section{Results and Discussion}

The compound that was isolated from the NMR sample as described above was also found to be present as a 10\% impurity in the original reaction mixture obtained from preparation of 2 . Although appearing to be a dimer on the basis of its NMR and mass spectra, its definitive structural characterization proved elusive and ultimately required X-ray crystallographic analysis for confirmation.

Characterization. The proton and carbon chemical shifts for dimer 6 are given in Scheme 3. The drawing reflects the geometry optimized with $\mathrm{MM}+$ in Hyperchem. The fluorine atoms are omitted for clarity. The 1,4-bis-difluoromethylene-anthracene and the 1,4-bis-difluoromethylenebenzene moieties were identified based on the proton-proton couplings and the proton-carbon couplings, seen in the selective decoupling, GHMQC and GHMBC spectra, respectively. The assignments of the protons in the benzene moieties were based on the nOes between 7.40 and 4.21, 5.70 on one hand, and between 6.74 and 6.02 on the other. A similar nOe is expected between 6.31 and 6.36, but cannot be observed because the chemical shifts are too close. At this point, it was unclear what satisfied the free valences on the quaternary carbon at 50.8, and on the methine carbon at 43.2, and therefore the sample was submitted for X-ray crystallography, which revealed the dimeric nature of the compound. As seen in Scheme 4, this structure accounts for the odd nOe seen between 6.74 and 5.70.

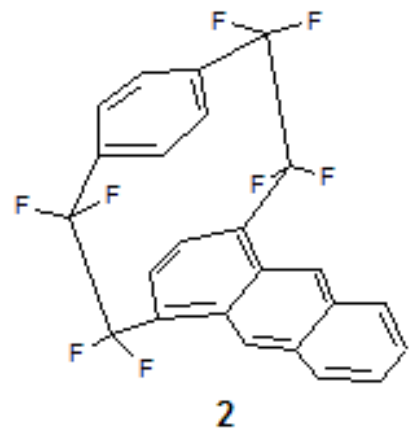

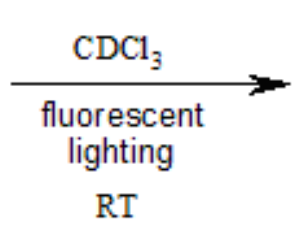

RT

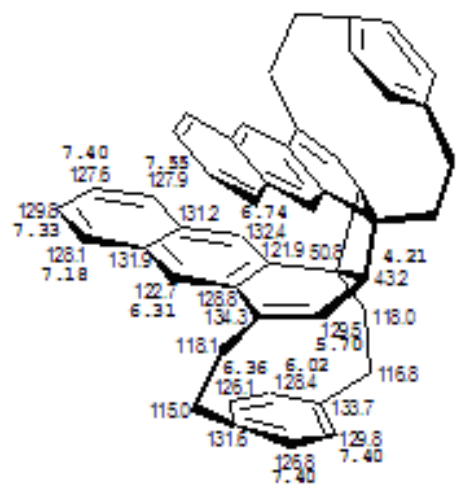

6 [fluorines omitted for clarity]

Scheme 4. Formation of dimmer 6. 


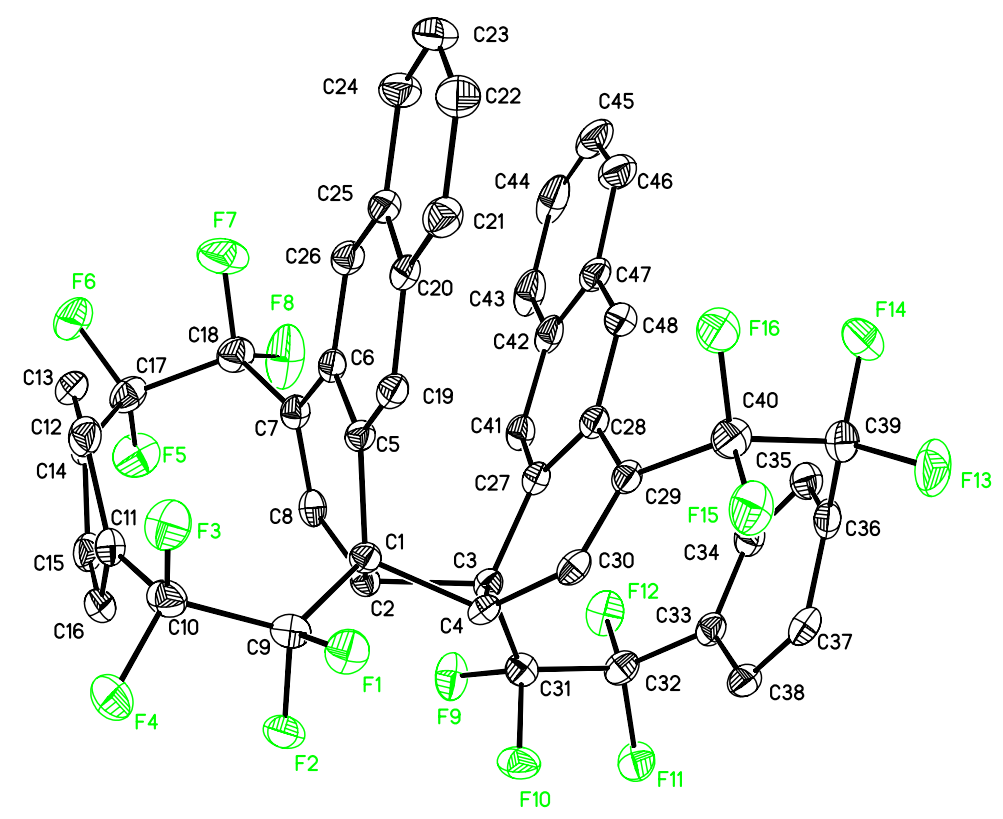

Figure 1. ORTEP drawing of dimer 6.

The X-ray diffraction analysis of the compound derived from $\mathbf{2}$ indicated that there were two molecules of $\mathbf{6}$ in its asymmetric unit. ${ }^{4}$ The aromaticity of the anthracene ring directly involved in the paracyclophane system was observed to be destroyed, with the two entities linked to each other in a head to tail fashion via a $[2+2]$ cycloaddition. For molecule A, the formed cyclobutane ring had a twist angle of $31.8^{\circ}$ and a torsion angle $\mathrm{C} 1-\mathrm{C} 2-\mathrm{C} 3-\mathrm{C} 4$ of $22.4^{\circ}$ to relieve the steric strain of the two bulky anthracene moieties. The two fluorine bridges $\mathrm{C} 1-\mathrm{C} 9-\mathrm{C} 10-\mathrm{C} 11$ and $\mathrm{C} 14-\mathrm{C} 17-\mathrm{C} 18-\mathrm{C} 7$ had torsion angles $40.1^{\circ}$ and $26.9^{\circ}$, respectively, in molecule A. The anthracene moiety in bonds C5-C1-C2-C8 and C27-C3-C4-C30 had torsion angles $29.5^{\circ}$ and $33.2^{\circ}$, respectively. The cyclobutane ring of molecule $\mathrm{B}$ had a twist angle of $23.5^{\circ}$ with torsion angles of $35.1^{\circ}$ and $20.6^{\circ}$ in the two fluorine bridges.

Dimer formation and chemistry. In principle, the dimer could have been formed by either a thermal or a photochemical [2 + 2] process. However, heating $\mathbf{2}$ at reflux in pentyl ether overnight in the dark did not lead to any significant dimer formation. Dimer 6 was itself thermally stable at temperatures up to $150{ }^{\circ} \mathrm{C}$. Above this temperature, 6 was observed to cleave cleanly back to monomer 2 with a rate constant of $9.8 \times 10^{-5} \mathrm{sec}^{-1}$ at $175^{\circ} \mathrm{C}$, which corresponds to a half life of 118 minutes. Thus dimerization cannot be a thermal process.

On the other hand, subjecting a chloroform solution of $\mathbf{2}$ to bright sunlight for one day led to some loss of $\mathbf{2}$ with formation of a complex mixture of products, which included dimer $\mathbf{6}$. When such a chloroform solution of $\mathbf{2}$ was exposed to simple fluorescent lighting for one week at room temperature, a clean 32\% conversion to dimer 6 was observed (Scheme 5). If the dimer is subjected to $u v$ light $(>356 \mathrm{~nm})$, a reversion to monomer 2 is observed, thus indicating a great sensitivity of the photoequilibrium of this system to the wavelength of light. 


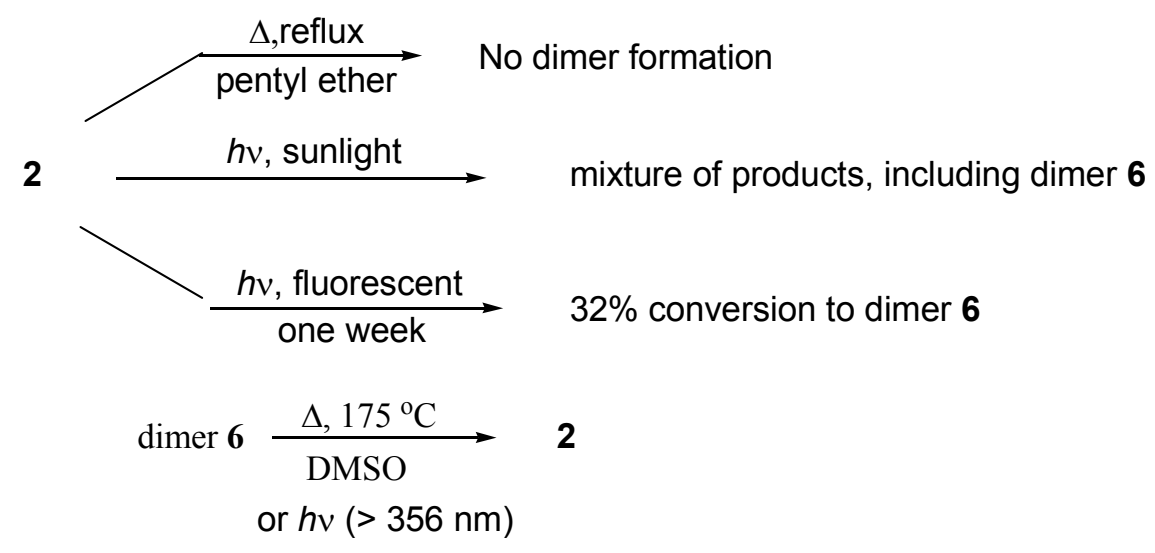

Scheme 5. Dimer formation and chemistry.

The photochemistry of anthracene and substituted derivatives of anthracene goes back to the work of Fritzsche in 1867, who observed the formation of an insoluble substance when solutions of anthracene were exposed to sunlight. ${ }^{5}$ Like 6, this substance was found to revert to anthracene upon heating (melting). Upon further examination, many years later, the product of this photoreaction was determined to be the symmetrical, "sandwich" dimer formed by linking both anthracenes at their 9, 10-positions. 6,7

Anthraceno-paracyclophane $\mathbf{2}$ is a pale yellow crystalline solid, and its unique photoreactivity likely derives from the fact that, with significant absorption extending well past $425 \mathrm{~nm}$, its uv spectrum extends into the visible region, whereas the naphthalenophanes, $\mathbf{4}$ and $\mathbf{5}$, are white solids with no absorption in the visible region, their absorptions extending only just past $350 \mathrm{~nm}$. Anthracenophane 3 is also yellow and might well be expected to exhibit similar photochemistry. However, its limited solubility at room temperature in all solvents thus far tested has precluded examination of its bimolecular photochemistry. If an appropriate solvent can be found that will allow such a study, it will be reported in the future.

The dimer itself is a white solid, thus explaining the photoequilibrium that is favorable to its formation from 2 in visible light.

Since the uv spectra of the fluorinated and non-fluorinated anthracenophanes do not differ significantly, it is expected that the hydrocarbon system analogous to $\mathbf{2}^{8-10}$ should exhibit analogous photodimerization reactivity.

Future work will also involve examination of the photochemistry of the two naphthalenophanes, $\mathbf{4}$ and 5, to see if analogous photodimerization processes may be observed for these two systems when using uv light. 


\section{Experimental Section}

Dimer 6. mp $150{ }^{\circ}(\mathrm{dec})\left(\right.$ turns yellow and slowly reverts to monomer 2); ${ }^{1} \mathrm{H}$ NMR, $\delta$ 7.60(d, $\mathrm{J}=8.1 \mathrm{~Hz}, 2 \mathrm{H}), 7.55(\mathrm{~d}, \mathrm{~J}=8.9 \mathrm{~Hz}, 2 \mathrm{H}), 7.40(\mathrm{ddd}, \mathrm{J}=8.0,6.9,1.2 \mathrm{~Hz}, 4 \mathrm{H}), 7.33(\mathrm{ddd}, \mathrm{J}=8.0,6.8$, $1.1 \mathrm{~Hz}, 2 \mathrm{H}), 7.18(\mathrm{~d}, \mathrm{~J}=7.7 \mathrm{~Hz}, 2 \mathrm{H}), 6.74(\mathrm{dd}, \mathrm{J}=3.1,1.5 \mathrm{~Hz}, 2 \mathrm{H}), 6.36(\mathrm{~d}, \mathrm{~J}=8.5 \mathrm{~Hz}, 2 \mathrm{H}), 6.31(\mathrm{~s}$, $2 \mathrm{H}), 6.02(\mathrm{~d}, \mathrm{~J}=8.4 \mathrm{~Hz}, 2 \mathrm{H}), 5.70(\mathrm{~d}, \mathrm{~J}=8.3 \mathrm{~Hz}, 2 \mathrm{H}), 4.21(\mathrm{~d}, \mathrm{~J}=7.0 \mathrm{~Hz}, 2 \mathrm{H}) ;{ }^{13} \mathrm{C} \mathrm{NMR}, \delta 134.3$, $133.7,132.4,131.9,131.2,129.8,129.5,127.9,127.6,129.8,128.1,122.7,128.8,128.4,131.6$, 128.4, 126.1, 118.1, 118.0, 116.8, 115.0, 50.8, 45.0, 43.2; MS (EI): m/z 452(21), 276(100), 176(49); HRMS (ESI-FT-ICR) Calc for C48H24F16 + Na 927.1515, found 927.1504; UV $\left(\mathrm{CH}_{2} \mathrm{Cl}_{2}\right): \lambda \max (\log \varepsilon)=358.1$ (3.22), 339.8 (3.64), 323.8 (3.97), 270.6 (4.55) nm.

X-ray experimental. Data for dimer 6 were collected at $173 \mathrm{~K}$ on a Siemens SMART PLATFORM equipped with a CCD area detector and a graphite monochromator utilizing $\mathrm{MoK}_{\alpha}$ radiation $(\lambda=0.71073 \AA$ ). Cell parameters were refined using up to 8192 reflections. A full sphere of data (1850 frames) was collected using the $\omega$-scan method $\left(0.3^{\circ}\right.$ frame width). The first 50 frames were re-measured at the end of data collection to monitor instrument and crystal stability (maximum correction on I was $<1 \%$ ). Absorption corrections by integration were applied based on measured indexed crystal faces.

The structure was solved by the Direct Methods in SHELXTL6, ${ }^{11}$ and refined using fullmatrix least squares. The non-H atoms were treated anisotropically, whereas the hydrogen atoms were calculated in ideal positions and were riding on their respective carbon atoms. The asymmetric unit consists of two chemically equivalent but crystallographically independent molecules, one molecule of dichloromethane in general position and another half disordered in two positions, in the asymmetric unit, around an inversion center. The latter half molecule could not be modeled properly, thus program SQUEEZE, ${ }^{12}$ a part of the PLATON ${ }^{13}$ package of crystallographic software, was used to calculate the solvent disorder area and remove its contribution to the overall intensity data. A total of 1180 parameters were refined in the final cycle of refinement using 25923 reflections with $\mathrm{I}>2 \sigma(\mathrm{I})$ to yield $\mathrm{R}_{1}$ and $\mathrm{wR}_{2}$ of $4.15 \%$ and $9.00 \%$, respectively. Refinement was done using $\mathrm{F}^{2}$.

CIF file containing X-ray structural data for dimer 6.

\section{Acknowledgements}

Support of this research in part by the National Science Foundation is acknowledged with thanks. KAA wishes to acknowledge the National Science Foundation and the University of Florida for funding of the purchase of the X-ray equipment. 


\section{References and Footnotes}

1. Roche, A. J.; Dolbier, W. R., Jr. J. Org. Chem. 1999, 64, 9137.

2. Battiste, M. A.; Duan, J.-X.; Zhai, Y.-A.; Ghiviriga, I.; Abboud, K. A.; Dolbier, W. R., Jr. J. Org. Chem. 2003, 68, 3078.

3. Zhai, Y.-A.; Ghiviriga, I.; Battiste, M. A.; Dolbier, W. R., Jr. Synthesis 2004, 2747.

4. The crystal structure data for dimer $\mathbf{6}$ has been deposited at the Cambridge Database: CCDC \# 277458. Data are available on request from the Director of the Cambridge Crystallographic Data Center, University Chemical laboratory, Lensfield Road, Cambridge CB2 1EW, U.K.

5. Fritzsche, J. J. Prakt. Chem. 1867, 44, 333.

6. Ehrenberg, M. Acta Crystallogr. 1966, 20, 177.

7. Cowan, D. O.; Drisko, R. L. Elements of Organic Photochemistry; Plenum Press: New York, 1976, p 37-47.

8. Toyoda, T.; Otsubo, I.; Otsubo, T.; Sakata, Y.; Misumi, S. Tetrahedron Lett. 1972, 1731.

9. Iwama, A.; Toyoda, T.; Otsubo, T.; Misumi, S. Chem. Lett. 1973, 587.

10. Iwama, A.; Toyoda, T.; Yoshida, M.; Otsubo, T.; Sakata, Y.; Misumi, S. Bull. Chem. Soc. Jpn. 1978, 51, 2988.

11. SHELXTL6 (2000). Bruker-AXS, Madison, Wisconsin, USA.

12. van der Sluis, P.; Spek, A. L. Acta Cryst. 1990, A46, 194.

13. Spek, A. L. Acta Cryst. 1990, A46, C-34. 